\title{
Hubungan antara Diameter Optic Nerve Sheath pada Grey Scale Ultrasound dengan Peningkatan Tekanan Intrakranial pada Pasien dengan Lesi Intrakranial
}

\section{The Correlation between Diameter of Optic Nerve Sheath on Grey Scale Ultrasound with Increased Intracranial Pressure in Patients with Intracranial Lesion}

\author{
Tatok Rudiharto ${ }^{1}$, Bachtiar Murtala ${ }^{1}$, Sri Asriyani ${ }^{1}$, Mirna Muis ${ }^{1}$, Cahyono Kaelan ${ }^{2}$, \\ Burhanuddin Bahar ${ }^{3}$ \\ ${ }^{I}$ Department of Radiology, Fakulty of Medicine, Hasanuddin University, Makassar \\ ${ }^{2}$ Department of Nerve, Fakulty of Medicine, Hasanuddin University, Makassar \\ ${ }^{3}$ Department of Public Health, Fakulty of Medicine, Hasanuddin University, Makassar \\ Email:dr_tatorudiharto@yahoo.com
}

KEYWORDS optic nerve sheath diameter, elevated intracranial pressure, ultrasonography

ABSTRACT The study aims to determine the correlation between diameter of optic nerve sheath on grey scale with increased intracranial pressure in patients with intracranial lesion. The research was conducted in Radiology Department of Dr. Wahidin Sudirohusodo Makassar from January 2019 May 2019. The sample were 39 people aged $\geq 18$ years old with intracranial lesion. Axial computed tomography (CT) examination was performed to evaluate intracranial lesions and the presence of midline shift. The diameter of the optic nerve sheath was measured using eye ultrasonography. Data analyses used Spearman's correlation test. The results showed that there was a correlation between the dilatation of the right and left optic nerve sheath diameter with midline shift ( $p=0.04 ; p$ $<0.05)$ on the diameter of the right optic nerve sheath showing a weak positive relationship $(p=0.02)$ for the diameter the optic nerve sheath left showing a medium positive relationship where the higher the midline shift, the wider the diameter of the left and right optical nerve sheath. There is a correlation between the right and left optic nerve sheath diameter ( $p=$ $<0.001)$ showing a strong positive relationship where the wider the diameter of the right optic nerve sheath, the wider the diameter of the left optic nerve sheath at high intracranial pressure. Statistically other results also obtained no relationship between dilatation of the diameter of the optic nerve sheath with clinical symptoms of increased intracranial pressure and type of lesion. 


\section{PENDAHULUAN}

\section{Pengunaan Ultrasonography}

(USG) dari optic nerve dan selubungnya (sheath) untuk mendiagnosis peningkatan tekanan intrakranial pada keadaan yang kritis, mulai banyak dipelajari dalam dua dekade terakhir. Diameter dari optic nerve sheath telah diketahui sebagai prediktor kuat dari peningkatan tekanan intrakranial (Dubourg, 2011). Nilai normalnya Optic nerve sheath diameter dikatakan kurang dari $5 \mathrm{~mm}$ dan optic nerve sheath diameter dikatakan abnormal bila diameternya $\geq 5 \mathrm{~mm}$.

Tekanan intrakranial (TIK) didefiniskan sebagai tekanan dalam rongga kranial. Menurut Morton et.al (2005), tekanan intrakranial normal adalah 0-15 mmHg, 3-7 mmHg pada anak dan 1,5-6 $\mathrm{mmHg}$ pada bayi. Nilai diatas $15 \mathrm{mmHg}$ dipertimbangkan sebagai peningkatan tekanan intrakranial. Tekanan intrakranial dipengaruhi oleh tiga faktor, yaitu otak (sekitar $80 \%$ dari volume total), cairan serebrospinal (sekitar 10\%) dan darah (sekitar 10\%) (Smith, 2008). Monro-Kellie doktrin menjelaskan tentang kemampuan regulasi otak yang berdasarkan volume yang tetap (Morton, et.al, 2005). Selama total volume intrakranial sama, maka TIK akan konstan. Peningkatan volume salah satu faktor harus diikuti kompensasi dengan penurunan faktor lainnya supaya volume tetap konstan. Perubahan salah satu volume tanpa diikuti respon kompensasi dari faktor yang lain akan menimbulkan perubahan TIK (Morton, et.al, 2005). Penyebab terjadinya peningkatan tekanan intrakranial dikarenakan peningkatan volume salah satu factor diatas yang tidak di ikuti respon kompensasi dari factor lain seperti adanya lesi intrakranial berupa: tumor intrakranial, perdarahan, infeksi, dan hidrocephalus (Sadoughi 2013). Ada dua metode pemantauan TIK yaitu metode invasif (secara langsung) dan non invasive (tidak langsung). Metode non invasif (secara tidak langsung) dilakukan pemantauan status klinis, neuroimaging (CT Scan dan MRI), Ultrasonography (ONSD) dan Funduscopy (Papilledema). Metode invasif (secara langsung) dapat dilakukan secara intraventrikular, intraparenkimal, subarakhnoid/subdural, dan epidural, berupa Intraparekimal microtransducer sensor, ventriculostomy dan dranase LCS.

Peningkatan tekanan intrakranial adalah kegawat daruratan dari cedera otak dengan diagnosis yang cepat memiliki pengaruh yang signifikan terhadap morbiditas dan mortalitas (Hwan, 2014).

Gejala klinik merupakan gejala yang pertama kali yang dikeluhkan pasien oleh adanya peningkatan TIK berupa : sakit kepala, muntah, defisit neurologis, bila peningkatan TIK berlanjut dan progresif berhubungan dengan penggeseran jaringan otak maka akan terjadi sindroma herniasi dan tanda-tanda umum Cushing's triad (hipertensi, bradikardi, respirasi ireguler) (Padayachy, 2010). Karena gejala klinis yang pertama kali muncul pada peningkatan tekanan intrakranial maka banyak klinisi menentukan peningkatan TIK hanya dari gejala klinis saja secara subjektif.

Midline shift adalah pergeseran garis tengah ke kontralateral akibat efek dari lesi pada intra axial atau extra axial sehingga mengakibatkan tekanan intrakranial meningkat, dan dapat dilihat pada foto CT scan dan MRI kepala dengan nilai normal $5 \mathrm{~mm}$. Ada beberapa struktur penting yang berhubungan dengan pergeseran midline shift yang harus di evaluasi yaitu septum pellucidum, ventrikel ketiga, dan kelenjar pineal (Geeraerts, 2007). 


\section{METODOLOGI}

Penelitian ini merupakan jenis penelitian desain Exploratif untuk menilai hubungan antara dilatasi optic nerve sheat berdasarkan grey scale ultrasonogrphy dengan gejala klinis peningkatan tekanan intrakranial pada pasien lesi intrakranial berdasarkan Computed Tomography Scan. Populasi sampel penelitian adalah semua pasien yang didiagnosis suspek adanya lesi intrakranial dengan gejala klinis peningkatan tekanan intrakranial dari gambaran klinis yang memenuhi kriteria inklusi yang datang kebagian radiologi RS. Dr. Wahidin Sudirohusodo Makassar untuk melakukan pemeriksaan CT Scan kepala dari bulan Januari 2019 sampai dengan Mei 2019.

Analisis data terdiri dari analisis deskriptif dilakukan untuk melihat karakteristik distribusi jumlah dan persentase untuk jenis kelamin, umur, gejala klinis peningkatan tekanan intrakranial, midline shift berdasarkan jenis lesi, nilai maxsimum dan minimum dari optic nerve sheath diameter bilateral. Analisis bivariat menggunakan uji Spearman.
ISI

Penelitian ini dilakukan di RS Dr. Wahidin Sudirohusodo Makassar dari bulan Januari 2019 sampai Mei 2019 dan didapatkan sebanyak 39 sampel.

Tabel 1 di atas memperlihatkan distribusi sample berdasarkan demografi. Terlihat bahwa distribusi berdasarkan jenis kelamin, sample dengan lesi intrakranial dan gejala klinis peningkatan tekanan intrakranial lebih banyak ditemukan pada jenis kelamin laki-laki sebanyak $21 \quad(53,8 \%)$ sample dibandingkan pada perempuan 18 (46,2\%) sample. Distribusi semple berdasarkan umur relatif merata pada semua kelompok umur. Pada tabel 2 berikut menunjukan sebaran sample berdasarkan karakteristik gejala klinis peningkatan tekanan intrakranial.

Tabel 2 di atas memperlihatkan distribusi berdasarkan gejala klinis peningkatan tekanan intrakranial. Sample dengan gejala klinis sakit kepala lebih banyak ditemukan 37 (94.9\%) sample. dari pada sample dengan gejala klinis gangguan penglihatan $20 \quad(51.3 \%)$ sample, muntah 17 (43.6\%) sample, deficit neurologis $(20,5 \%)$ sample. Pada tabel 3 berikut menunjukan sebaran sample berdasarkan karakteristik jenis lesi intrakranial dan ada atau tidaknya midlie shift pada setiap lesi. 
Tabel 1. Distribusi umur dan jenis kelamin pada subyek penelitian

\begin{tabular}{lccc}
\hline & Kategori & $\mathrm{n}$ & $\%$ \\
\hline Jenis kelamin & Laki-laki & 21 & 53.8 \\
& Perempuan & 18 & 46.2 \\
\hline Umur (Tahun) & $17-25$ & 7 & 17,9 \\
& $26-35$ & 8 & 20,5 \\
& $36-45$ & 7 & 17,9 \\
& $46-55$ & 8 & 20,5 \\
& $56-65$ & 7 & 17,9 \\
& $>65$ & 2 & 5,1 \\
\hline
\end{tabular}

Keteranga : $\mathrm{n}:$ jumlah, $\%$ : persentase, Sumber : data primer

Tabel 2. Distribusi gejala klinis peningkatan tekanan intrakranial pada subyek penelitian

\begin{tabular}{lcc}
\hline \multicolumn{1}{c}{ Gejala klinis } & $\mathrm{n}$ & $\%$ \\
\hline Sakit Kepala & 37 & 94.9 \\
Muntah & 17 & 43.6 \\
Gangguan penglihatan & 20 & 51.3 \\
Defisit neurologis & 8 & 20.5 \\
\hline
\end{tabular}

Keteranga : $\mathrm{n}:$ jumlah, $\%$ : persentase, Sumber : data primer

Tabel 3. Distribusi midline shift berdasarkan jenis lesi intracranial

\begin{tabular}{lccc}
\hline Jenis lesi & \multicolumn{3}{c}{ Midline shift } \\
\hline Tumor & $\mathrm{n}$ & $(+)$ & $(-)$ \\
Pendarahan & 19 & $10(52,6 \%)$ & $9(47,4 \%)$ \\
Edema Cerebri & 8 & $2(25,0 \%)$ & $6(75,0 \%)$ \\
Infeksi & 9 & $3(33,3 \%)$ & $6(66,7 \%)$ \\
Hidrocephalus & 8 & $3(37,5 \%)$ & $5(62,5 \%)$ \\
\hline
\end{tabular}

Keteranga : $\mathrm{n}:$ jumlah, \% : persentase, (+) : ada mdlne sift, (-) : tidak ada midline shift. Sumber : data primer

Tabel 3 di atas memperlihatkan distribusi midline shift berdasarkan jenis lesi intrakranial, pada jenis lesi intrakranial, tumor $10(52,6 \%)$ sample, pada lesi perdarahan $2(25,0 \%)$ sample, Pada edema cerebri 3 (33,3\%) sample, pada Infeksi 3 (37,5\%) sample, pada Hidrocephalus $4(30,8 \%)$ sample, sehingga frekwensi adanya midline shift berdasarkan jenis lesi berupa tumor lebih banyak di antara lesi yang lain dan distribusi semple berdasarkan pada jenis lesi intrakranial tanpa midline shift relatif merata. Pada tabel 4 berikut menunjukan distribusi sample berdasarkan nilai minimum, maksimum dan mean dari optic nerve sheath diameter kanan dan kiri.

Tabel 4 di bawah memperlihatkan distribusi pada 39 subyek penilitian yang 
diteliti optic nerve sheath diameter kanan mempunyai rentang nilai $(4.70 \mathrm{~mm}-$ $7,20 \mathrm{~mm})$ dengan mean $(5,85 \mathrm{~mm})$ sedangkan optic nerve sheath diameter kiri mempunyai rentang nilai $(4,80 \mathrm{~mm}-$ $7,10 \mathrm{~mm})$ dengan mean $(5,94 \mathrm{~mm})$. Pada tabel 5 berikut menunjukan sebaran sample berdasarkan nilai mean dari optic nerve sheath diameter kanan dan kiri dengan gejala klinis peningkatan tekanan intracranial

Tabel 5 di bawah memperlihatkan distribusi nilai mean antara gejala klinis peningkatan tekanan intrakranial dengan diameter optic nerve sheath kanan dan kiri gejala klinis sakit kepala dengan optic nerve sheath diameter kanan nilai mean $(5.88 \mathrm{~mm})$ dan kiri nilai mean $(5.910 \mathrm{~mm})$. Muntah nlai mean kanan $(5.81 \mathrm{~mm})$ dan kiri nilai mean $(5.91 \mathrm{~mm})$. Penurunan penglihatan nlai mean kanan $(5.81 \mathrm{~mm})$ dan kiri nilai mean $(6.01 \mathrm{~mm})$. deficit neurologi nlai mean kanan (5.75 $\mathrm{mm})$ dan kiri nilai mean $(5.80 \mathrm{~mm})$. Pada tabel 6 berikut menunjukan distribusi sample berdasarkan nilai mean dari optic nerve sheath diameter kanan dan kiri dengan jenis lesi intrakranial.

Tabel 4. Distribusi nilai minimum, maksimum dan mean dari ONSD kanan dan kiri pada subyek penelitian

\begin{tabular}{lccccc}
\hline & $\mathrm{n}$ & $\begin{array}{c}\text { Minimum } \\
(\mathrm{mm})\end{array}$ & $\begin{array}{c}\text { Maximum } \\
(\mathrm{mm})\end{array}$ & $\begin{array}{c}\text { Mean } \\
(\mathrm{mm})\end{array}$ & $\begin{array}{c}\text { Standar Deviasi } \\
(\mathrm{mm})\end{array}$ \\
\hline Orbita Kanan & 39 & 4.70 & 7.20 & 5.85 & 5.75 \\
Orbita Kiri & 39 & 4.80 & 7.10 & 5.94 & 5.59 \\
\hline
\end{tabular}

Keteranga : $\mathrm{n}:$ jumlah, Sumber $:$ data primer

Tabel 5. Distribusi nilai mean ONSD kanan dan kiri berdasarkan gejala klinis peningkatan tekanan intracranial

\begin{tabular}{lccccc}
\hline \multicolumn{1}{c}{ Gejala klinis } & \multicolumn{3}{c}{ ONSD kanan } & ONSD kiri \\
\hline & $\mathrm{n}$ & $\begin{array}{c}\text { Mean } \\
(\mathrm{mm})\end{array}$ & $\begin{array}{c}\text { Standart } \\
\text { Deviasi } \\
(\mathrm{mm})\end{array}$ & $\begin{array}{c}\text { Mean } \\
(\mathrm{mm})\end{array}$ & $\begin{array}{c}\text { Standart Deviasi } \\
(\mathrm{mm})\end{array}$ \\
Sakit Kepala & 37 & 5.88 & 5.78 & 5.98 & 5.48 \\
Muntah & 17 & 5.81 & 4.86 & 5.92 & 5.18 \\
Gangguan penglihatan & 20 & 5.82 & 5.27 & 6.01 & 4.84 \\
Deficit neurologi & 8 & 5.75 & 4.34 & 5.80 & 3.62 \\
\hline
\end{tabular}

Keteranga : $\mathrm{n}$ : jumlah, Sumber : data primer 
Tabel 6. Distribusi nilai mean ONSD kanan dan kiri berdasarkan jenis lesi intracranial

\begin{tabular}{lccccc}
\hline \multicolumn{1}{c}{ Jenis lesi } & \multicolumn{2}{c}{ ONSD kanan } & \multicolumn{2}{c}{ ONSD kiri } \\
\hline Tumor & $\mathrm{N}$ & $\begin{array}{l}\text { Mean } \\
(\mathrm{mm})\end{array}$ & $\begin{array}{c}\text { Standart } \\
\text { Deviasi } \\
(\mathrm{mm})\end{array}$ & $\begin{array}{c}\text { Mean } \\
(\mathrm{mm})\end{array}$ & Standart Deviasi (mm) \\
Pendarahan & 19 & 5.84 & 4.60 & 5.93 & 4.75 \\
Edema Cerebri & 8 & 5.72 & 6.88 & 5.86 & 6.48 \\
Infeksi & 9 & 6.00 & 6.42 & 6.17 & 5.61 \\
Hidrocephalus & 13 & 6.18 & 6.11 & 6.24 & 4.78 \\
\hline
\end{tabular}

Keteranga : $\mathrm{n}:$ jumlah, Sumber : data primer

Tabel 7. Hubungan antara ONSD kanan dan kiri dengan gejala klinis peningkatan tekanan Intracranial

\begin{tabular}{lcccc}
\hline \multicolumn{1}{c}{ Gejala klinis } & \multicolumn{2}{c}{ ONSD kanan } & \multicolumn{2}{c}{ ONSD kiri } \\
\hline & $\mathrm{P}$ & $\mathrm{r}$ & $\mathrm{P}$ & $\mathrm{r}$ \\
Sakit kepala & 0.14 & 0.24 & 0.08 & 0.28 \\
Muntah & 0.78 & -0.05 & 0.92 & 0.01 \\
Gangguan penglihatan & 0.69 & -0.06 & 0.48 & 0.12 \\
Difisit neurologis & 0.72 & -0.06 & 0.39 & -0.14 \\
\hline
\end{tabular}

Data diolah dengan uji korelasi Spearman's dengan batas kemaknaan $\mathrm{p}<0.05$., Sumber : Data primer.

Tabel 6 di atas memperlihatkan distribusi nilai mean pada jenis lesi dengan diameter optic nerve sheath. Pada jenis lesi tumor dengan optic nerve sheath diameter kanan nilai mean $(5.84 \mathrm{~mm})$ dan kiri nilai mean $(5.93 \mathrm{~mm})$. Pada perdarahan, nilai mean kanan $(5.72 \mathrm{~mm})$ dan kiri nilai mean $(5.86 \mathrm{~mm})$. Edema cerebri nlai mean kanan $(6.00 \mathrm{~mm})$ dan kiri nilai mean $(6.17 \mathrm{~mm})$. Infeksi nlai mean kanan $(6.18 \mathrm{~mm})$ dan kiri nilai mean $(6.23 \mathrm{~mm})$. Hidrocephalus nlai mean kanan $(6.08 \mathrm{~mm})$ dan kiri nilai mean $(6.18 \mathrm{~mm})$. Pada edema cerebri, infeksi, hidrocephalus yang disertai peningktan tekanan intrakranial mengakibatkan dilatasi ONSD kanan dan kiri > 6mm. Pada tabel 7 berikut menunjukan hubungan dari optic nerve sheath diameter kanan dan kiri dengan gejala klinis peningkatan tekanan intrakranial.

Tabel 7 di atas memperlihatkan bahwa pada hasil uji Spearman's tidak terdapat hubungan yang bermakna antara diameter optic nerve sheath kanan dan kiri dengan semua gejala klinis peningkatan tekanan intrakranial diperoleh nilai $\mathrm{p}>0.05$ Pada tabel 8 berikut menunjukan hubungan dari optic nerve sheath diameter kanan dan kiri dengan jenis lesi intrakranial dan midline shift.

Pada penelitian ini menunjukan bahwa tidak terdapat hubungan antara dilatasi optic nerve sheath diameter bilateral dengan gejala klinis peningkatan tekanan intrakranial yaitu sakit kepala, muntah, gangguan penglihatan, defisit neurologi, Hal ini sesuai dengan beberapa penelitian sebelumnya yang dilakukan $S i$ Un Lee, Jin Pyeong joen dan dkk. Dengan hasil ONSD tidak ada hubungan secara signifikan menurut usia, jenis kelamin, gejala klinis dan jenis lesi yang mendasarinya (Si Un Lee et. al.2016). 

DENGAN LESI INTRAKRANIAL

Tabel 8. Hubungan ONSD kanan dan kiri dengan Jenis lesi intrakranial dan midline shift

\begin{tabular}{lcccc}
\hline \multicolumn{1}{r}{ Jenis lesi } & \multicolumn{2}{c}{ ONSD kanan } & \multicolumn{2}{c}{ ONSD kiri } \\
\hline Tumor & $\mathrm{P}$ & $\mathrm{r}$ & $\mathrm{P}$ & $\mathrm{r}$ \\
Perdarahan & 0.52 & 0.11 & 0.69 & 0.07 \\
Edema cerebri & 0.23 & -0.19 & 0.28 & -0.18 \\
Hidrocephalus & 0.13 & 0.25 & 0.36 & 0.15 \\
Infeksi & 0.09 & 0.27 & 0.09 & 0.28 \\
Letak lesi & 0.07 & 0.29 & 0.08 & 0.28 \\
Midline shift & 0.66 & -0.07 & 0.41 & 0.14 \\
\hline
\end{tabular}

Data diolah dengan uji korelasi Spearman's dengan batas kemaknaan $\mathrm{p}<0,05$, Sumber : Data primer.

Tabel 9. Hubungan ONSD kanan dengan ONSD kiri pada peningkatan tekanan intracranial

\begin{tabular}{lccc}
\hline & \multicolumn{3}{c}{ ONSD Kiri } \\
\hline \multirow{2}{*}{ ONSD Kanan } & $\mathrm{P}$ & $\mathrm{r}$ & $\mathrm{N}$ \\
& $<0,001$ & 0,792 & 39 \\
\hline
\end{tabular}

Data diolah dengan uji korelasi Spearman's dengan batas kemaknaan $\mathrm{p}<0,05$.Sumber : Data primer.

Tabel 8 di atas memperlihatkan bahwa pada hasil uji Spearman's terdapat hubungan yang bermakna antara diameter optic nerve sheath kanan dan kiri dengan midline shift dibuktikan nilai $\mathrm{p}(0.04)$ pada diameter optic nerve sheath kanan dengan kekuatan hubungan positif lemah dengan nilai $\mathrm{r}$ sebesar $(0.33)$ dan nilai $\mathrm{p}$ sebesar (0.02) pada diameter optic nerve sheath kiri dengan kekuatan hubungan positif sedang dengan nilai $r$ sebesar (0.48) dimana makin jauh midline shift maka makin lebar diameter optic nerve sheath kanan dan kiri.

Pada penelitian ini menunjukan bahwa terdapat hubungan yang bermakna antara diameter optic nerve sheath kanan dan kiri dengan midline shift dengan nilai $\mathrm{p}(<0.05)$ dan menunjukan bahwa makin besar midline shift maka makin lebar diameter optic nerve sheath kanan dan kiri. Hal ini sesuai dengan beberapa penelitian sebelumnya yang dilakukan $S i$ Un Lee, Jin Pyeong joen dan $\mathrm{dkk}$ meneliti dengan umur $>18$ tahun dan pasien dengan peningkatan tekanan intrakranial dengan adanya gambaran midline shift pada CT scan kepala. Dengan hasil dilatasi ONSD ada hubungan secara signifikan dengan adanya lesi intrakranial disertai adanya midline shift (Si Un Lee et.al. , 2016). Pada perdarahan disertai adanya midline shift pada CT scan kepala ada hubunganya dengan dilatasi optic nerve sheath diameter. Pada jenis lesi intrakranial berupa tumor, pedarahan, edema cerebri, hydrocephalus, infeksi dan juga letak lesi tidak terdapat hubungan yang bermakna dengan diameter optic nerve sheath kanan dan kiri pada hasil uji Spearman's dengan nilai $\mathrm{p}(>0.05)$. Hal ini sesuai dengan 
beberapa penelitian sebelumnya yang dilakukan Si Un Lee, Jin Pyeong joenet. al. Dengan hasil ONSD tidak ada hubungan secara signifikan menurut usia, jenis kelamin, gejala klinis dan jenis lesi yang mendasarinya. Pada tabel 9 berikut diperlihatkan hubungan dari optic nerve sheath diameter kanan dengan kiri pada peningkatan tekanan intrakranial.

Table 9 di atas memperlihatkan bahwa pada hasil uji Spearman's menunjukan terdapat hubungan yang bermakna antara diameter optic nerve sheath kanan dan kiri dengan dibuktikan nilai $\mathrm{p}(<0.001)$ dan menunjukan bahwa terdapat kekuatan hubungan positif kuat dimana makin lebar diameter optic nerve sheath kanan maka makin lebar juga diameter optic nerve sheath kiri dibuktikan dengan nilai $\mathrm{r}$ (0.792). yang menyimpulkan bahwa makin besar diameter optic nerve sheath kanan makin besar juga diameter optic nerve sheath kiri pada tekanan intrakranial yang tinggi.

Pada penelitian ini menunjukan bahwa terdapat hubungan yang bermakna antara diameter optic nerve sheath kanan dan dimana makin lebar diameter optic nerve sheath kanan maka makin lebar diameter optic nerve sheath kiri serta menyimpulkan bahwa tidak ada perbedaan pengukuran optic nerve sheath diameter antara mata kanan dengan mata kiri pada peningkatan tekanan intrakranial. Hal ini sesuai dengan beberapa penelitian sebelumnya yang dilakukan beberapa oleh Venkatakrishna at al, Vivek et al, Riccardo et al, dan Kimberly at al bahwa pengukuran optic nerve sheath diameter dapat dipakai mengevaluasi peningkatan tekanan intrakranial (Asghar et al., 2015; Ismail, 2015).

\section{PENUTUP}

Terdapat hubungan antara midline shift dengan diameter optic nerve sheath dimana makin besar midline shift maka makin lebar diameter optic nerve sheath kanan dan kiri. Tidak ada perbedaan diameter optic nerve sheath antara mata kanan dengan mata kiri pada peningkatan tekanan intrakranial sehingga dapat dilakukan pada salah satu orbita saja. Semua kasus dengan peningkatan tekanan intrakranial mengakibatkan dilatasi ONSD kanan dan kiri > $5 \mathrm{~mm}$. Semua lesi yang bersifat difus pada intrakranal yang menyebabkan peningkatan tekanan intrakranial mengakibatkan dilatasi ONSD kanan dan kiri > $5 \mathrm{~mm}$. Secara statistik tidak terdapat hubungan antara diameter optic nerve sheath dengan umur, jenis kelamin, jenis lesi, letak lesi dan gejala klinis peningkatan tekanan intrakranial.

\section{DAFTAR PUSTAKA}

Asghar, A., Madiha, H., Hussain Alia. 2015. Optic nerve sheath diameter evaluated by transorbital Sonography in healthy volunteers from Pakistan. Anaesth, Pain \& Intensive Care; 19(3):14-23

Dubourg, J., Javouhey, E., Geeraerts, T., Messerer, M., Kassai, B. Ultrasonography of optic nerve sheath diameter for detection of raised intrakranial pressure: a systematic review and metaanalysis. Intensive Care Med. 2011;37(7):1059-1068. Available from: $\quad$ http://dx.doi.org/10. 1007/s00134-011-2224-2.

Geeraerts, T., Launey Yoann L, Martin Laurent, Pottecher Julien, Vigué Bernard, Duranteau Jacques, 
Benhamou. 2007. Ultrasonography of the optic nerve sheath may be useful for detecting raised intrakranial pressure after severe brain injury. Intensive Care Med. 33:1704-1711.

Hwan, K.Y., Ho Lee, J., Kun Hong, C.,Won Cho, K., Hoon Yeo, J., Ju Kang, M. Feasibility of optic nerve sheath diameter measured on initial brain computed tomography as an early neurologic outcome predictor after cardiac arrest. Acad Emerg Med. 2014;21(10):1121-1128. Available from: http://dx.doi.org/10.1111/acem.124 77.

Ismail, A.2014. Transorbital Sonographic Measurement of Normal Optic Sheath Nerve Diameter in Nigerian Adult Population. Malays J Med Sci. 21(5): 24-29.

Padayachy, L., Figaji, A.A., Bullock, M.R. 2010. Intrakranial pressure monitoring for traumatic brain injury in the modern era. Childs Nerv Syst. 26:441-452.

Sadoughi, A., Rybinnik, I., Cohen, R. 2013. Measurement and Management of Increased Intrakranial Pressure. The Open Critical Care Medicine Journal, 2013, 6, (Suppl 1: M4) 56-65.

Si Un Lee, Jin Pyeong Jeon, Hannah Lee, Jung Ho Han, Mingu Seo, Hyoung Soo Byoun, Won-Sang Cho, Ho Geol Ryu, Hyun-Seung Kang, Jeong Eun Kim, Heung Cheol Kim, Kyung-Sool Jang. 2016. Optic nerve sheath diameter threshold by ocular ultrasonography for detection of increased intrakranial pressure in Korean adult patients with brain lesions. Medicine. 95(41):e5061

Smith, M. 2008. Monitoring Intrakranial Pressure in Traumatic Brain Injury. International Anesthesia research Society.106(1):240-248. 